\title{
Building Simulation to Measure Indoor Microclimate in Heritage Buildings
}

\author{
Kristian Fabbri ${ }^{1}$, Marco Pretelli ${ }^{1}$, Anna Bonora ${ }^{1}$ \\ ${ }^{1}$ University of Bologna, Bologna, Italy
}

\begin{abstract}
The aim of this paper is to describe our Building Simulation (BS) approach to study indoor microclimate parameters in heritage buildings. Literature already exists over this subject: in the area of museums - Thomson, Camuffo; this issue has been particularly emphasized, for example, by Bernardi; others, as De Guichen, proposed specific methodologies for museums. Nevertheless, in our opinion, today there isn't a vision which includes the history and the objectives of the architecture. We consider indoor microclimate in heritage buildings as a result of several strategies to guarantee indoor comfort. We named it "Historic Indoor Microclimate", and we adopt BS to simulate actual, past and future indoor microclimate. In this paper we show three case studies of Italian historic buildings: Villa La Petraia, Florence; Villa Barbaro, Maser; Palace of Venaria Reale, Turin, which can clarify the importance of the application of the BS on cultural heritage. Moreover, the paper proposes an index: "Heritage Microclimate Risk", useful to study the indoor microclimate aggressiveness.
\end{abstract}

\section{Introduction}

Nowadays it is becoming increasingly clear the need of a proper management of historic buildings: ensuring the conservation of the cultural heritage and guarantying the thermal comfort of the occupants. The preservation of an historic building depends largely on its microclimatic conditions.

The study of the indoor microclimate of heritage buildings involves some problems. We are specifically interested about the ones related to the impact on the artworks (paintings, furniture, frescos, etc.), in relation to specific agents (physical, chemical, biological) which can damage them and whose presence, concentration and diffusion.

That depends on the characteristics of the indoor microclimate and it's influenced by the management of artworks - and of the buildings that host them - and the tourists in relation to the relevant artistic path.

This problem has long been known in scientific literature, specific to museums (Thomson, 1986; Camuffo, 1998; Bernardi, 2008; Corgnati and Filippi, 2010; D'Agostino, 2015; Litti, Audenaert and Fabbri 2017; Lucchi 2017) and there exist Standards (UNI 10829 EN 15759-1), which identify the range of the values, allowing the preservation of the individual works (e.g. books, paintings) or materials (e.g. ceramics, papyrus manuscripts) in relation to their nature. Indeed, sometimes, to ensure microclimate control on the artefacts, special showcases are provided in case of higher risks due to decay and use.

Moreover, nowadays, the indoor microclimate control can be provided by HVAC system (Heating Ventilation and Air-Conditioning) for the winter/summer air conditioning, if the characteristics of the building and/or frequency of visitors are such as to justify their on/off activation or their implementation.

In different contexts, the artworks are housed in several rooms, and they belong to the building and to the visitors' path. The microclimate of these rooms can be "kept under control" thanks to the technical HVAC. Nevertheless, sometimes the HVAC system is not enough. This kind of problems involves also the management of the artworks borrow for museum expositions.

In this paper, we propose a new index, the "Heritage Microclimate Risk" (HMR), to define a unique tool to evaluate indoor microclimate aggressiveness for building, furniture, painting, etc. It permits to evaluate the risk level to whom the objects are exposed and the level of the human's comfort, in order to improve it, through the help of hypothetical scenarios, realized by the BS.

This article, thanks to the experience reported by the case studies -Villa La Petraia, Florence; Villa Barbaro, Maser; Palace of Venaria Reale, Turin-, shows how the Building Simulation can be useful to face those mentioned categories of problems: we propose a methodology, based on the use of the virtual BS on cultural heritage, which permits to pre-emptively define, throughout a virtual building model, which actions could aid the preservation of the heritage buildings, avoiding the risk component that would be taken working on the physical building.

\section{Methods}

The proposed methodology is composed of three phases:

1. Understanding the building, through:

a. archive research: to verify the geometrical, structural and thermo-physical characteristics of the historic building;

b. on-site relief: to obtain the building geometric measurement;

c. on-site monitoring: to record, using probes, the Actual Indoor Microclimate (AIM) characteristics, following the definition of Pretelli and Fabbri); 
2. Virtual Building modelling and simulation:

a. Building Simulation: construction of a 3D Virtual Building model, trough any modelling software, and of Virtual Environment model in dynamic conditions (Building Energy Simulation, CFD), using IES.VE software, to reproduce the same characteristics of the case study;

b. Model validation: to validate the model, comparing the simulated data to the ones obtained through the indoor microclimate campaign;

c. Virtual Scenarios: if the virtual building model gets validated through the data collected with the microclimate indoor monitoring, the study of the Heritage Microclimate Risk (HMR) can proceed, along with the scenarios of management and/or modification of the indoor microclimate;

3. Calculating the Heritage Microclimate Risk (HMR). The environmental parameters recorded by probes are: Air Temperature (measured in ${ }^{\circ} \mathrm{C}$ ), Relative Humidity (measured in \%), Illuminance (measured in lux) and Carbon Dioxide $\left(\mathrm{CO}_{2}\right.$ measured in $\left.\mathrm{ppm}\right)$.

Moreover, the virtual model gives the opportunity to simulate other variables, even if not measured by the probe, such as the distribution of the air velocity in the space (to assess any phenomena of turbulence and/or handling of the dust) and/or water vapour content, and/or mean radiant temperature and/or natural light distribution (illuminance).

The validation process consists in the comparison of the measured data -by probes, during the monitoring campaign- with the simulated ones -obtained using the software IES.VE (Integrated Environmental Solutions)-. The validation parameters are:

- $\mathrm{MBE}$ (Mean Bias Error),

$$
M B E=\frac{\sum_{i=1}^{n}\left(M_{i}-s_{i}\right)}{\sum_{i=1}^{n} M_{i}}
$$

Validated if $\mathrm{MBE}<10 \%$;

- Coefficient of Variation root-mean-square error (RMSE):

$$
C V(R M S E)=\frac{\sqrt{\sum_{\mathrm{i}=1}^{\mathrm{n}}\left[\frac{\left(M_{i}-S_{i}\right)^{2}}{\dot{N}_{i}}\right]}}{\frac{\sum_{i=1}^{n} M_{i}}{n}}
$$

Validated if CV (RMSE) $<30 \%$;

- Pearson Correlation Coefficient:

$$
\text { PEARSON }=\frac{\sigma_{M S}}{\sigma_{M} \sigma_{S}}
$$

if $>0.7=$ strong correlation,

if between $0.3-0.7=$ correlation;

- Coefficient of determination $\mathrm{R}^{2}$ :

$$
R^{2}=\frac{\sum_{i=1}^{n}\left(S_{i}-\bar{M}\right)^{2}}{\sum_{i=1}^{n}\left(M_{i}-\bar{M}\right)^{2}}
$$

When the model is validated, the accuracy of the Building Simulation, with respect to the variables used in validation, is confirmed

The thermal characteristics of the models are automatically calculated by the software once we specify all the construction components (stratigraphy materials and thickness).

The environment of an indoor space is affected by the outdoor climate too. Indeed, on IES.VE, it is necessary to choose the weather file whose data are got from the nearest meteorological station from each case study. Moreover, it is fundamental setting information about the geographical location and the HVAC system (set-point, daily profile, etc.). In this way it is possible to obtain a virtual model, which has the same environmental characteristics of the original space of the studied architecture. That permits to realize Building Simulations and to assume present, future and past environmental scenarios, simulating the state of conservation of the building, of the artworks and the occupants' comfort: we can evaluate what could happen changing certain materials of the building; the management of the HVAC system; taking in consideration the Climate Change and its consequences on the specific indoor microclimate; etc.

Finally, to calculate the HMR is useful to estimate the aggressiveness of the microclimate against the materials hosted in a specific indoor microclimate. It is calculated as follows:

$$
H M R=\frac{m r_{h}}{h}[\%]
$$

and regarding the single variable $(\mathrm{x})$

$$
H M R_{(x)}=\frac{m r_{h_{(x)}}}{h}[\%]
$$

where:

$\mathrm{mr}_{\mathrm{h}} \quad$ is the hourly microclimate risk of the reference period;

$\mathrm{h}$ represents the total hours of the reference period.

In the case study presented in this paper, the reference period corresponds to the monitoring campaign.

The $\mathrm{mr}_{\mathrm{h}}$ (hourly microclimate risk) is determined by

$$
\begin{aligned}
& \quad m r_{h}=\sum_{j=1}^{n}\left(h r_{(x)}>h r_{(x, \text { set }), \min }\right)_{j}+\left(h r_{(x)}<\right. \\
& \left.h r_{(x, \text { set }), \max }\right)_{j}[\mathrm{~h}]
\end{aligned}
$$

Where

" $h r_{(x)}$ " is the heritage risk of the microclimatic variable (x);

"hr $(\mathrm{x}, \mathrm{set})$ min" is the heritage risk of the microclimatic variable ( $\mathrm{x}$ ) with the minimum set-point, defined as the lower range established by Standard (UNI 10829, 1999) or other guidelines;

" $h r_{(x, s e t), \max }$ " is the heritage risk of the microclimatic variable $(\mathrm{x})$ with the maximum set-point defined as the lower range established by Standard (UNI 10829, 1999) or other guidelines;

" $\mathrm{j}$ " is the number of hours of the reference period.

Validated if $\mathrm{R}^{2}>0.5$ 
The proposed HMR follows the parameter defined by Corgnati et al (2009): the authors defined the performance index: "PI, defined as the percentage of time in which the measured parameter lies within the required (tolerance) range" ; but, while this was later used only to validate the capacities of air conditioning systems to fulfil the imposed limits, we tried to use it to evaluate the conservation conditions, in order to adopt it not for museums but for historic buildings.

This index allows to organize the distribution of the artworks in a heritage building: it helps to decide if a specific room could be suitable for hosting artworks or collections, with the final goal to improve the preventive conservation of the building and its content.

\section{Results}

\section{Villa La Petraia, Florence, Italy}

The first case study, developed with the help of Eng. Cinzia Magnani and Arch. Leila Signorelli, as research assistants from the Department of Architecture of the University of Bologna, has been Villa La Petraia (UNESCO World Heritage), built at the end of XV century in Florence, Italy. This building has been characterised by many transformations over the years: once completed, in 1544, it becomes propriety of Medici family, who used the Villa as a private house; in the XIX century, Savoy family bought the Villa and they decided to cover the central courtyard, through a glass and metal structure. This change of the Villa's shape had consistent consequences on the indoor microclimate of the historic building.
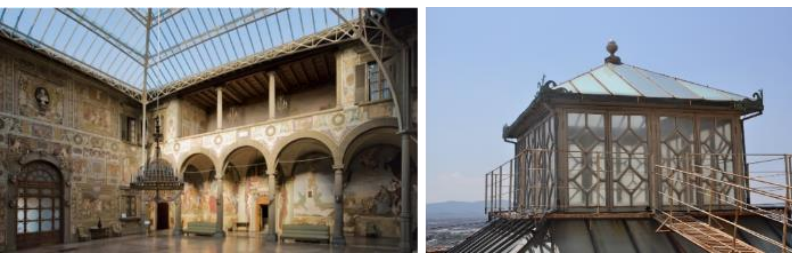

Figure 1: glass-and-metal covering.

Indeed, the elimination of the cover in the central courtyard implies changes in the convective motions in the rooms towards the court, as well as the effects of solar radiation and external temperature on the loggiato, again towards the court. A further level of analysis, requested by the Director of the Sovraintendenza, has been to evaluate microclimate in other rooms to inform the decision to change place to furniture or paintings.
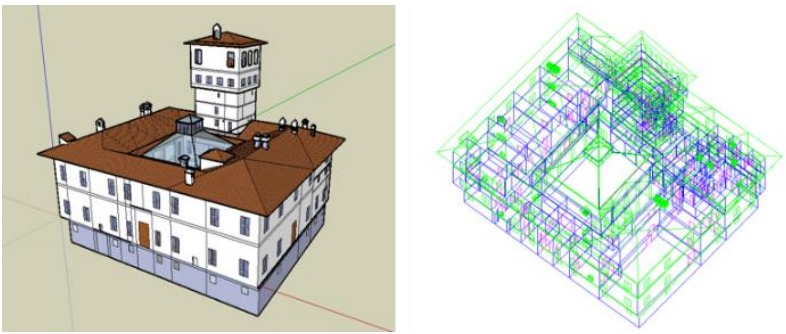

Figure 2: 3D model on SketchUp (left) and on IES.VE (right).

The monitoring campaign lasted from 22/07/2015 to $23 / 03 / 2016$. The HVAC system is not active. In this specific case the most interesting aspect to evaluate is the differences -due to the addition of the covering in the courtyard- in the current indoor microclimate compared to the past one, which represents the Original Indoor Microclimate (OIM) of the Villa as it has been planned and wanted by the Medici family.

Therefore, we compared the scenario obtained through the $\mathrm{BS}$, considering the historical configuration of the building -with no covering in the courtyard- with the current climatic data (2015) and the scenario still with the same shape of the building in XIX century, but with the historic climatic data, from 1650. Current climatic data are from ARPA and the historic ones have been deduced by the researches of Camuffo and Bertolin (2012).

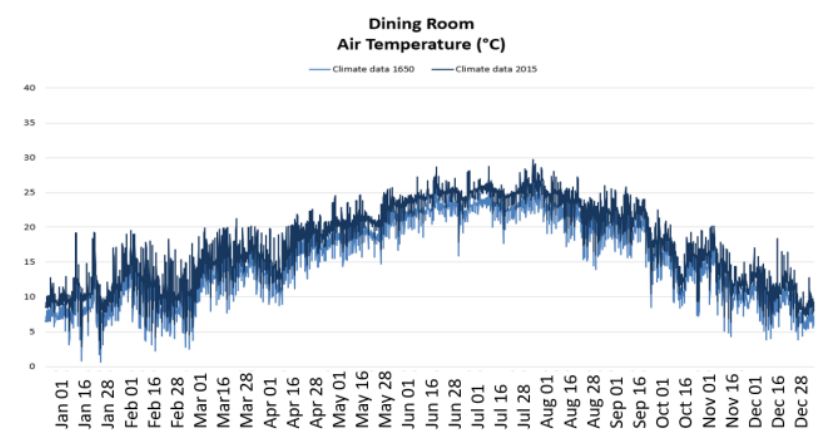

\section{Figure 3: thermal trend comparison, Dining room,} IES.VE simulation.

The Figure 3 shows as, by the simulation realised using the historical data (1650), we obtain a thermal trend which reproduce the one obtained if we put in the data of 2015 , but with lower temperatures: the difference is about 1$2{ }^{\circ} \mathrm{C}$. This gap, produced in 365 years of climate changes, however small, has to be considered in relation to the building's modification which could be done in the future. The second confrontation is between the scenarios of the building with and without the covering, using for both the climatic data of 2015 .

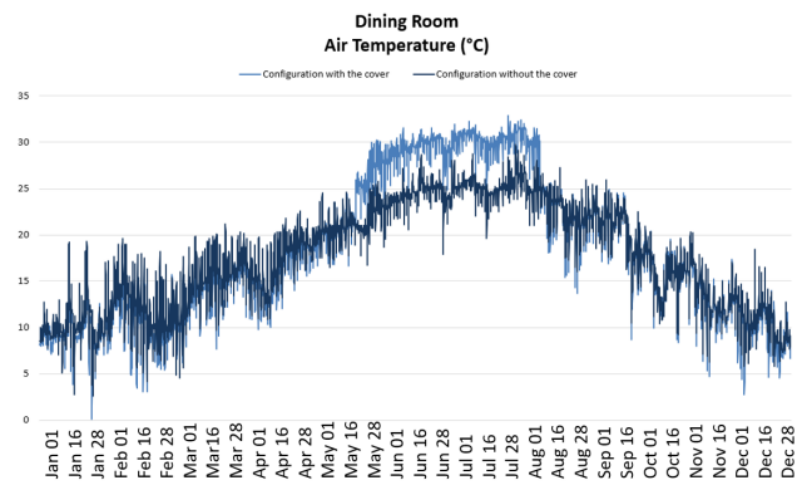

Figure 4: thermal trend comparison, Dining room, IES.VE simulation.

Figure 4 presents that we have thermal differences between: a minimum of $2-3^{\circ} \mathrm{C}$ (during the winter months) and a maximum of $10^{\circ} \mathrm{C}$ (in summer). Therefore, the introduction of the cover in the courtyard causes a significant augmentation of the indoor air temperatures. On the other hand, as shown by the Figure 5, the reduction of the relative humidity due to the presence of the 
covering is not equally important: from $2-3 \%$ in winter to $10 \%$ in summer.

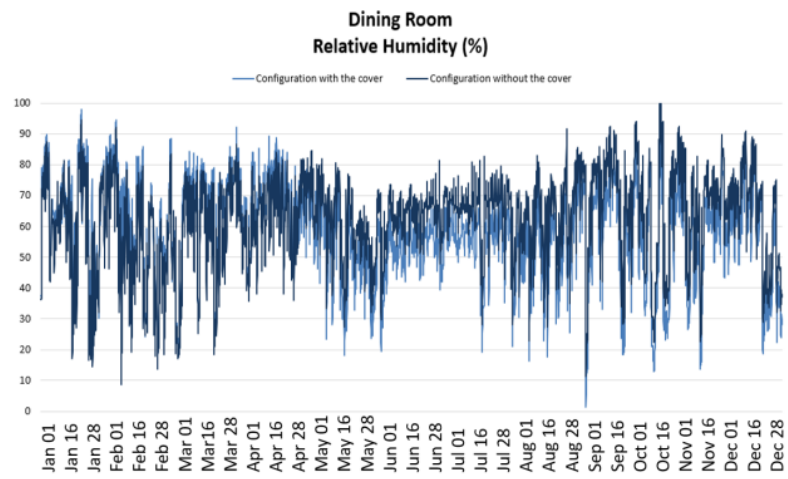

Figure 5: Relative Humidity trend comparison, Dining room, IES.VE simulation.

Moreover, the addition of the cover results to raise the level of HMR, as shown in Table1, reported in "Annex Tables".

Of course, these conditions influence also the comfort of the visitors: considering the Actual Indoor Microclimate (AIM) (2015) the Predicted Mean Vote (PMV) calculated by IES.VE, through the Computational Fluid Dynamics (CFD) simulation, shows, taking the dining room as example, a discomfort during summer, in the area near the door which look out on the courtyard; during the winter the comfort condition is worse: there is a general discomfort and the most important data is the condition recorded between the two doors on the north. This is a crucial area for the visitors' tour of the Villa and there we record a PMV of $-2,5$. For the CFD we chose the warm and the coldest day of the year (according to the results of the Apache simulation).
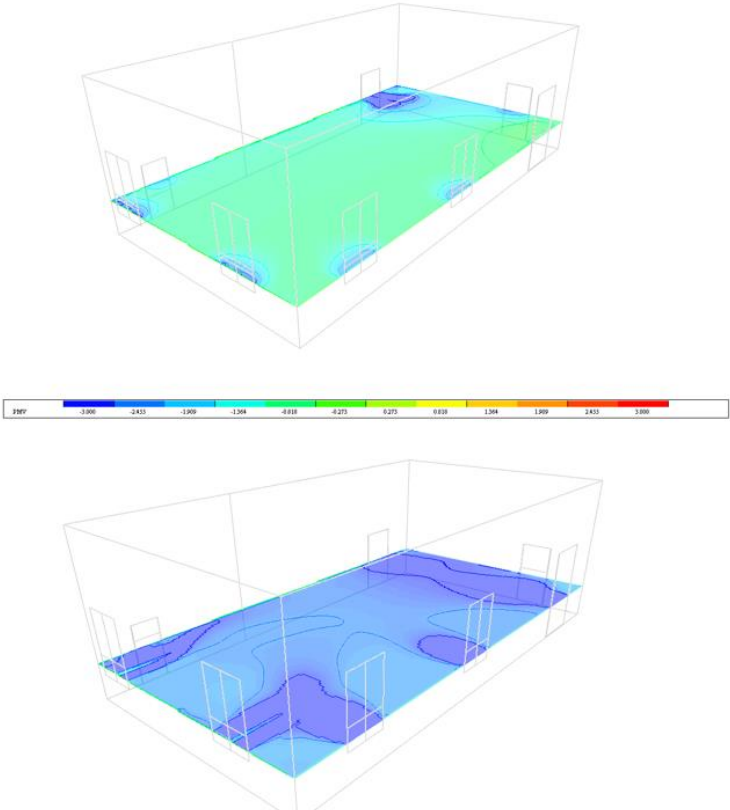

Figure 6: PMV in summer (on the top) and in winter (on the bottom), Dining room, IES.VE simulation.

Villa Barbaro, Maser (TV), Italy
The second case study is Villa Barbaro, built in Maser (TV, Italy) between 1554 and 1560 by the architect Andrea Palladio and registered in the UNESCO World Heritage Site list since 1996, as Palladian Villa of Veneto. The novelty of this research, also compared to the one just described, is the development and the definition of a single indicator for the risk due to the indoor microclimate: HMR. The Villa is characterised by the presence of numerous frescoes, indeed the HMR has been calculated with the aim to verify its current preservation conditions and to maintain or improve them.
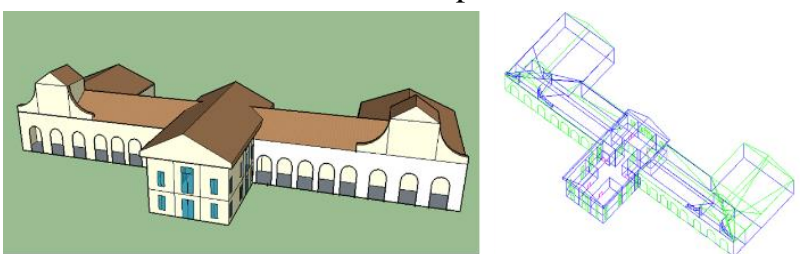

Figure 7: 3D model on SketchUp (left) and on IES.VE (right)

The monitoring campaign lasted from 21/06/2016 to $9 / 12 / 2016$. We monitored three of the six rooms open to the public -the rest of the Villa is used as a residential private building-. The building has a HVAC system, a heating system with fan-coils, introduced during the $50 \mathrm{~s}$ of the XX century. In the studied rooms, HVAC system is always off, so it can't be taken into consideration.

In the two monitored rooms, "Croce Centrale" and "Tribunale D'Amore", the data which have proved to be the most interesting are those of the indoor air temperature. Indeed, the HMR calculated for the frescos hosted in these rooms is respectively: $86,91 \%$ and $84,38 \%$ for air temperature; $32,31 \%$ and 33,78 for relative humidity. The baseline ranges used for $\mathrm{T}$ and $\mathrm{RH}$ are those set out in UNI 10829 and MIBACT, for the category "inorganic materials/articles":

- $\quad$ Air Temperature $\mathrm{hr}_{(\mathrm{t}, \mathrm{set}) \min }=15^{\circ} \mathrm{C} \quad$ and $\mathrm{hr}_{(\mathrm{t}, \text { set }) \text { max }}=25^{\circ} \mathrm{C}$;

- Relative Humidity $\mathrm{hr}_{(\mathrm{RH}, \mathrm{set}) \text { min }}=20 \%$ and $\mathrm{hr}_{(\mathrm{RH}, \text { set }) \text { max }}=60 \%$.

Defining the level of HMR, with an our proposal of HMR hazard classification ( $<25 \%$ low risk; $25 \%-50 \%$ moderate risk; $50 \%-75 \%$ marked risk; $>75 \%$ extreme risk), the microclimatic risk caused by the air temperature corresponds to a "Extreme risk"; whereas the one caused by relative humidity is a "moderate risk". In our point of view, a low risk (sensitive area) correspond to a microclimate where a cultural heritage's object has always been kept for a long period of time, without evidence of damage, and to which it became acclimatised. 


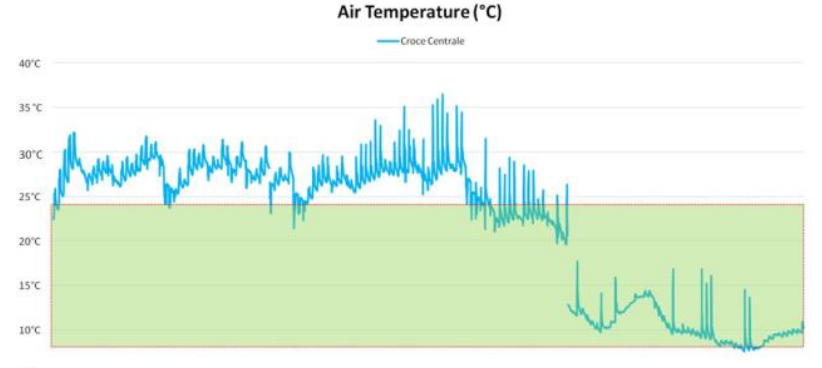

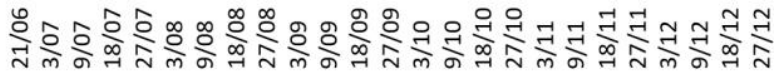

Figure 8: Air Temperature trend and Standard range,

HVAC off, room Croce Centrale, IES.VE simulation.

Figure 8 shows the air temperatures data recorded by probes during the monitoring campaign. The green area represents the range indicated in UNI 10829 and MIBACT as the optimal temperatures suggested for the conservation of frescoes.

If we set the software IES.VE with the input of "HVAC on", setting the set-point of $24^{\circ} \mathrm{C}$ and $14^{\circ} \mathrm{C}$, the building simulation's result will be a temperature which respects the suggested range.

This condition would lead to an improvement of the visitors' comfort too (Figure 10), but this option will never be applied, and it will remain an example of the use of BS to study the indoor microclimate of heritage buildings. Indeed, when an artefact has been in specific microclimatic conditions for a long time (in the case of Villa Barbaro we are talking about ages), it tends to create internal tensions which probably negatively respond to any sudden climate and microclimate change. The activation of the HVAC system will improve the level of visitors' comfort (Figure 9), but it would in fact risk to compromise the artefacts.

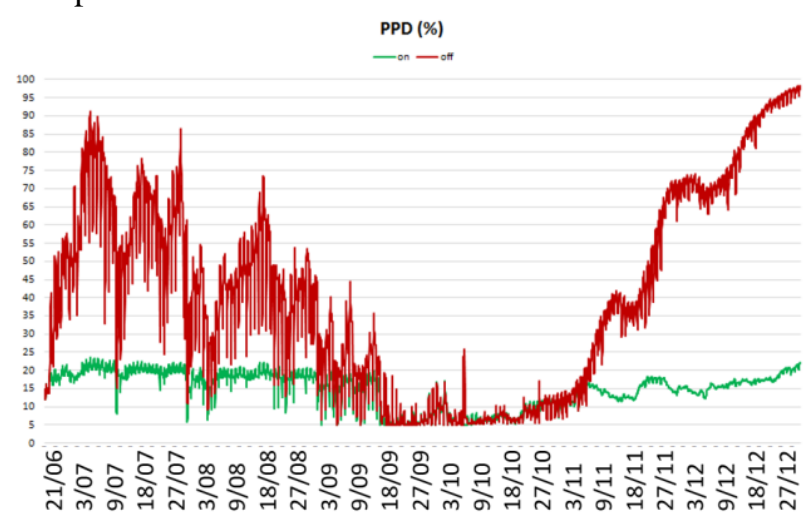

Figure 9: PPD Simulation, HVAC on-off, room Croce Centrale, IES.VE simulation.

When the aim is to improve the human comfort, this kind of solutions are useful and quite easy to manage, but if the conservation of the artefacts represents the priority, taking decisions and evaluating any possible effects will be harder.

\section{Palace of Venaria Reale, Venaria (TO), Italy}

The third case study is the Royal Palace of Venaria Reale (Piedmont, Italy). This architecture, restored recently
2001-2007), is the result of the work of six architects, between 1659 and 1798: Amedeo Castellamonte, Michelangelo Garove, Filippo Juvarra, Benedetto Alfieri, Giuseppe Battista Piacenza and Carlo Randoni. Thanks to the help of the Center of Conservation and Restoration (CC\&R) of Venaria Reale we have had the chance to use indoor microclimatic data, recorded from 2007 to 2017 of two rooms, which we analysed for our research: Room 33 and Room 38.

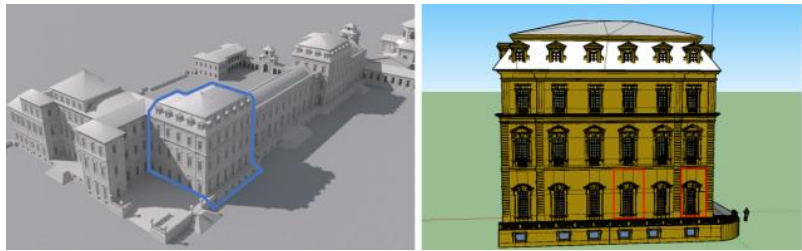

Figure 10: studied partition of the Palace (render realised in 3D Studio Max, on the left and $3 D$ model realised through SketchUp, on the right).

The blue line in Figure 10 underlines the part of the building where the studied rooms are located, and the red lines confines these rooms: 38 on the left and 33 on the right.

We compared the 2017 indoor microclimate to a hypothetical future one: in 2100, which would be produced if the climate increased by $1.5^{\circ} \mathrm{C}$ (Figure 11). Here, in addition to the visitors' comfort -which would change a little, but not significantly-, we considered: the consequences on the HMR for the materials hosted in these two rooms; on the temperature and on the relative humidity.

It turns out that the Climate change doesn't serious damage to the indoor microclimate of this historic building, if it the HVAC is active.

\section{$-\mathrm{T}\left({ }^{\circ} \mathrm{C}\right)$ hvac on $\quad \mathrm{T}\left({ }^{\circ} \mathrm{C}\right)$ hvac on +1.5}

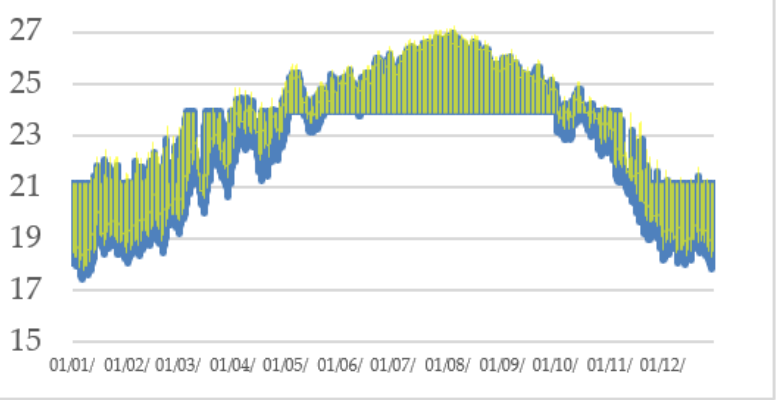

Figure 11: $T\left({ }^{\circ} \mathrm{C}\right)$ Simulation, HVAC on, Room 33.

Indeed, the mean difference of the indoor temperature on one year is of $0.28^{\circ} \mathrm{C}$, with peak of $0.8^{\circ} \mathrm{C}$ : if there were a rise of $1.5^{\circ} \mathrm{C}$ of the climate, we can just suppose a reduction of heating costs.

On the contrary, considering the HVAC system off, we would have a mean difference of the indoor temperature of $1.45^{\circ} \mathrm{C}$, with a minimum peak of 0.69 and a maximum of 1.58. Data of Figure 12 must be considered as a wakeup call: without activating the HVAC system, the effect of the Climate change on the indoor microclimate, could affect the artefacts conservation too. 


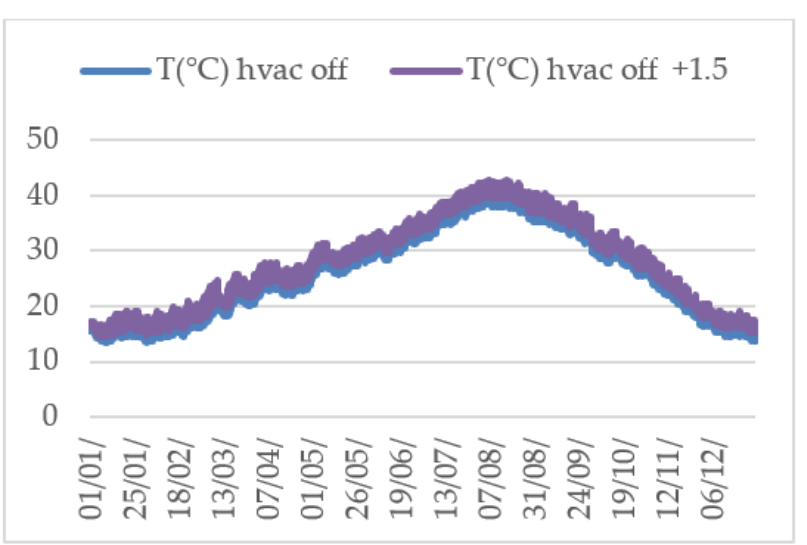

Figure 12: $T\left({ }^{\circ} \mathrm{C}\right)$ Simulation, HVAC off, Room 33.

Table 2 shows that the biggest gap between 2017 and 2100 of Relative Humidity occurs when the HVAC system is active, on the contrary, when it is off, we obtain the maximum gap of the Temperature between the two analysed scenarios. Considering HVAC off, the maximum gap of relative humidity $(1.87 \%)$ has a little influence, but the maximum augmentation of the temperature in $2100(1.58 \%)$ could be a problem for the conservation of the building's artefacts. To evaluate that possibility, we also calculated and compared the HMR of each scenario (the specific tables' data are reported in the page before the Nomenclature section).

It appears that the HMR in 2100 will be more aggressive of $+1 \%$ and $+3 \%$. We can resume Table 3 like this:

HVAC on: $\mathrm{HMR}_{\mathrm{T}} 2100<0,01 \mathrm{HMR}_{\mathrm{T}} 2017$;

$\mathrm{HMR}_{\mathrm{RH}} 2100<0,02 \mathrm{HMR}_{\mathrm{RH}} 2017$.

HVAC off: $\mathrm{HM}_{\mathrm{RT}} 2100>0,002 \mathrm{HM}_{\mathrm{RT}} 2017$;

$\mathrm{HMR}_{\mathrm{RH}} 2100>0,03 \mathrm{HMR}_{\mathrm{RH}} 2017$.

This kind of process results useful to establish which objects could be hosted in a museum permanently or just for temporary exhibitions.

\section{Discussion}

The proposed methodology has proved to be applicable to different case studies and useful to evaluate decisions about the management of the historic buildings, with the aim to guarantee optimal people's comfort conditions and the preservation of buildings and of the artworks guarded inside them.

Moreover, the results of simulations evaluation and the HMR allow to define the conservation strategies and exposure of the artworks, according to three purposes:
- Screening: to simulate the annual average value, minimum and maximum, of one or more variables, for each room in the building, aiming to assess if indoor microclimate values are outside of the range of tolerance for the conservation defined by ministerial guides, by the scientific literature or other;

- Targeted: Once you choose the room in which it was decided to put the artworks, based on criteria relating to the museum exhibition, the artistic path, the will of the curator or anything else. It can be evaluated through the virtual model specific micro-climatic conditions are suitable for the conservation of artworks, permanently or for the duration of the exposure in the case of temporary exhibitions; or in the case of other activities with a sensitive increasing of the number of visitors.

- Verification: in the case of rooms where there are works which show the traces of degradation caused by time, or compare due to poor comfort conditions and use of the room, or in case of doubts about any parameters microclimate (air speed and dust deposit, the water content and vapour condensation risk, etc.) the virtual model permits to verify the physical environment variables.

\section{Conclusion}

This paper focuses attention on the advantages related to a microclimatic approach to the preservation of existing historic materials and to ensure the visitors' thermal comfort, having the chance to consider the original conditions of the buildings and to take into account possible future scenarios, through the BS: once you acquire the knowledge of the indoor microclimate, it is possible to verify and to simulate the people's comfort and the state of conservation of the building and its artworks. In this way, the BS allows to define how to intervene on the building, knowing in advance the consequences of our actions.

\section{Acknowledgments}

The authors would like to thank Arch. Leila Signorelli and Eng. Cinzia Magnani; the last owner of Villa Barbaro, Countess Diamante Luling Buschetti; the CC\&R of La Venaria Reale, for their willingness and their support. 
Table 1: Villa La Petraia, HMR (\%) of RH and T: 2015-1650

\begin{tabular}{|c|c|c|c|c|}
\hline \multicolumn{5}{|c|}{ Dining room: HMR (\%) } \\
\hline $\begin{array}{c}\text { RH 1650 (without } \\
\text { cover) }\end{array}$ & T 2015 (with cover) & 1650 (without cover) \\
\hline $\begin{array}{c}\text { All Materials } \\
\text { MIBACT\&UINI10890 }\end{array}$ & $29,70 \%$ & $25,57 \%$ & $26,77 \%$ & $23,03 \%$ \\
\hline $\begin{array}{c}\text { Oil on canvas } \\
\text { MIBACT }\end{array}$ & $24,81 \%$ & $25,53 \%$ & & \\
\hline $\begin{array}{c}\text { Oil on canvas } \\
\text { UNI10890 }\end{array}$ & $26,13 \%$ & $25,50 \%$ & $29,40 \%$ & $28,49 \%$ \\
\hline $\begin{array}{c}\text { Oil on canvas } \\
\text { MIBACT\&UNI10890 }\end{array}$ & $19,89 \%$ & $17,67 \%$ & & \\
\hline Wood MIBACT & $22,74 \%$ & $21,31 \%$ & $29,40 \%$ & $28,49 \%$ \\
\hline Wood UNI10890 & & $25,01 \%$ & $29,40 \%$ & $2,49 \%$ \\
\hline $\begin{array}{c}\text { Wood } \\
\text { MIBACT\&UNI10890 }\end{array}$ & $25,48 \%$ & & & \\
\hline Fabrik (silk) MIBACT & & & & \\
\hline
\end{tabular}

Table 2: Venaria Reale, $T$ and RH comparison between 2017-2100

\begin{tabular}{|c|c|c|c|c|}
\hline \multicolumn{5}{|c|}{ Room 33: Differences between 2017-2100 } \\
\hline & T-HVAC ON & RH-HVAC ON & T-HVAC OFF & RH-HVAC OFF \\
\hline Min. & 0.00 & 0.00 & 0.69 & 0.00 \\
\hline Max & 0.80 & 5.72 & 1.58 & 1.83 \\
\hline Mean & 0.28 & 2.60 & 1.45 & 0.26 \\
\hline
\end{tabular}

Table 3: Venaria Reale, HMR (\%) of RH and T: 2017-2100, HVAC ON (on the top) - HVAC OFF (on the bottom)

\begin{tabular}{|c|c|c|c|c|}
\hline \multicolumn{5}{|c|}{ Room 33: HMR (\%) - HVAC ON } \\
\hline & RH 2017 & RH 2100 & T 2017 & 2100 \\
\hline $\begin{array}{c}\text { All Materials } \\
\text { MIBACT\&UINI10890 }\end{array}$ & $3 \%$ & $5 \%$ & $15 \%$ & $18 \%$ \\
\hline $\begin{array}{l}\text { Oil on canvas } \\
\text { MIBACT }\end{array}$ & $29 \%$ & $25 \%$ & & \\
\hline $\begin{array}{c}\text { Oil on canvas } \\
\text { UNI10890 }\end{array}$ & $35 \%$ & $34 \%$ & & \\
\hline $\begin{array}{c}\text { Oil on canvas } \\
\text { MIBACT\&UNI10890 }\end{array}$ & & & $31 \%$ & $30 \%$ \\
\hline Wood MIBACT & $25 \%$ & $21 \%$ & & \\
\hline Wood UNI10890 & $26 \%$ & $23 \%$ & & \\
\hline $\begin{array}{c}\text { Wood } \\
\text { MIBACT\&UNI10890 }\end{array}$ & & & $31 \%$ & $30 \%$ \\
\hline Fabrik (silk) MIBACT & $38 \%$ & $38 \%$ & $31 \%$ & $30 \%$ \\
\hline \multicolumn{5}{|c|}{ Room 33: HMR (\%) - HVAC OFF } \\
\hline $\begin{array}{c}\text { All materials } \\
\text { MIBACT\&UNI10890 }\end{array}$ & $0.16 \%$ & $0.23 \%$ & $61 \%$ & $58 \%$ \\
\hline $\begin{array}{l}\text { Oil on canvas } \\
\text { MIBACT }\end{array}$ & $15 \%$ & $15 \%$ & & \\
\hline $\begin{array}{c}\text { Oil on canvas } \\
\text { UNI10890 }\end{array}$ & $27 \%$ & $27 \%$ & & \\
\hline $\begin{array}{c}\text { Oil on canvas } \\
\text { MIBACT\&UNI10890 }\end{array}$ & & & $83 \%$ & $86 \%$ \\
\hline Wood MIBACT & $14 \%$ & $14 \%$ & & \\
\hline Wood UNI10890 & $14 \%$ & $15 \%$ & & \\
\hline $\begin{array}{c}\text { Wood Oil } \\
\text { MIBACT\&UNI10890 }\end{array}$ & & & $83 \%$ & $86 \%$ \\
\hline Fabrik (silk) MIBACT & $38 \%$ & $38 \%$ & $83 \%$ & $86 \%$ \\
\hline
\end{tabular}




\section{Nomenclature}

Abbreviations:

BS: Building Simulation

HVAC: Heating Ventilation and Air-Conditioning

HMR: Heritage Microclimate Risk

AIM: Actual Indoor Microclimate

CFD: Computational Fluid Dynamics

IES.VE: Integrated Environmental Solutions

MBE: Mean Bias Error

CV (RMSE): Coefficient of Variation (Root-Mean-

Square Error)

$\mathrm{R}^{2}$ : Coefficient of determination $\mathrm{R}^{2}$

OIM: Original Indoor Microclimate

PMV: Predicted Mean Vote

CC\&R: Center Conservation and Restoration

\section{References}

Ankersmit B S.M.H.L., Managing Indoor Climate Risks in Museums, Springer, International Publishing, Amsterdam, 2017.

ASHRAE, ASHRAE Guideline 14-2002 Measurement of Energy and Demand Savings, Ashrae. 8400 (2002) 170.

ASHRAE, Energy Guideline for Historical Buildings, (2015) 66.

Bernardi A., Microclimate Inside Cultural Heritage Buildings, Padua, 2008.

Bonacina C, Baggio P., Cappelletti F., Romagnoni P., Stevan A.G., The Scrovegni Chapel: The results of over 20 years of indoor climate monitoring, Energy and Buildings, 95 (2015) 144-152.

Camuffo D., Microclimate for Cultural Heritage, Amsterdam, 1998.

Camuffo D. \& Bertolin C., The earliest temperature observations in the world: the Medici Network (16541670), Climatic Change, V.111, pp. 335-363, 2012.

Camuffo D. \& Bertolin C., The earliest spirit-in-glass thermometer and a comparison between the earliest CET and Italian observations, Weather, Vol. 67, No. 8, pp.206-209, August 2012.

Corgnati S.P., Fabi V., Filippi M, A methodology for microclimatic quality evaluation in museums: Application to a temporary exhibit, Building and Environmental 44 (2009) 1253-1260.

Corgnati S.P., Filippi M.-, Assessment of thermohygrometric quality in museums: Method and in-field application to the "Duccio di Buoninsegna" exhibition at Santa Maria della Scala (Siena, Italy), Journal of Cultural Heritage 11 (2010) 345-349.

D’Agostino V., D’Ambrosio Alfano F.R., Palella B.I., Riccio G., The museum environment: A protocol for evaluation of microclimatic conditions, Energy and Buildings, 95 (2015) 124-129.
Fabbri K., Pretelli M., Heritage buildings and historic microclimate without HVAC technology: Malatestiana Library in Cesena, Italy, UNESCO Memory of the World, Energy and Buildings, 76 (2014) 15-31.

Ferdyn-Grygierek J., Monitoring of indoor air parameters in large museum exhibition halls with and without airconditioning systems, Building and Environmental, 107 (2016) 113-126

IES.VE, https://www.iesve.com/ (Last visit 4/1/2018), (n.d.).

Judkoff R., BESTEST: Test Procedures "Building Energy Simulation” Tools, 2014 Build. Technol. Off. Peer Rev. . (2014). https://energy.gov/sites/prod/files/2014/10/f18/emt62 _Judkoff_042214.pdf.

Litti G., Audenaert A., Fabbri K, Indoor Microclimate Quality (IMQ) certification in heritage and museum buildings: The case study of Vleeshuis museum in Antwerp, Building and Environmental, 124 (2017) 478-491.

Lucchi E., Multidisciplinary risk-based analysis for supporting the decision-making process on conservation, energy efficiency, and human comfort in museum buildings, Journal of Cultural Heritage, 22 (2016) 1079-1089

Lucchi E., Review of preventive conservation in museum buidings, Journal of Cultural Heritage, 29 (2017) 114.

Martínez-Molina A., Tort-Ausina I., Cho S., Vivancos J.L., Energy efficiency and thermal comfort in historic buildings: A review, Renew. Sustain. Energy Rev. 61 (2016) 70-85.

MIBACT, MIBACT, Ministerial Decree, Atto di indirizzo sui criteri tecnico-scientifici e sugli standard di funzionamento e sviluppo dei musei, 10th May 2001, (2001).

Pavlogeorgatos G., Environmental parameters in museums, Building and Environmental, 38 (2003) 1457-1462.

Pretelli M, Fabbri K., Historic Indoor Microclimate of the Heritage Buildings: A Guideline for Professionals who care for Heritage Buildings, Springer, 2018 doi:10.1007/978-3-319-60343-8.

Ruzi G.R., Bandera C.F, Validation of Calibrated Energy Models: Common Errors, Energies, 10, 1587(2017) 219

Thomson G., The museum environment, 2nd ed., London, 1986.

UNI EN 15757:2013, Conservazione dei Beni Culturali Specifiche concernenti la temperatura e l'umidità relativa per limitare i danni meccanici causati dal clima ai materiali organici igroscopici, (2013). 